\title{
Knowledge Innovative Organization: The Effect of Constant Organization Renewal
}

\author{
Abu Saleh Md. Sohel-Uz-Zaman ${ }^{1}$, Umana Anjalin $^{2}$ \\ ${ }^{1}$ United International University, Dhaka, Bangladesh; ${ }^{2}$ The University of Asia Pacific, Dhaka, Bangladesh. \\ Email: sohelzaman@gmail.com,umana@uap-bd.edu
}

Received May 28, 2009; revised July 7, 2009; accepted August 14, 2009.

\begin{abstract}
The term 'knowledge' is getting increased importance as the economy is becoming progressively knowledge intensive. Contemporary view of innovation management is acknowledging knowledge as the most effective source of innovation. Success of the business depends on how successfully knowledge is used for innovation. As a result, organizations are increasingly embracing knowledge strategy for their innovation scheme. Incorporating knowledge in the innovation process; building innovative capabilities and identifying essential features of a knowledge innovative organization are the key concerns of this study. Knowledge is a context specific notion. In this case study, the use of knowledge for innovation has been analyzed from an individual organization point of view so that contextual elements of a knowledge innovative organization can be identified more precisely along with the institutional implications. Thus, this article would be able to provide a good number of meaningful indications in using knowledge for innovation; it would also shed light on constant capability building for innovation; nurturing of creativity and developing of knowledge infrastructure of a knowledge innovative organization. In addition, this study will be revealing the true nature of knowledge strategy and its application in the context of a developing country.
\end{abstract}

Keywords: Innovation, Knowledge, Knowledge-Innovative Organization (KIO), Knowledge Strategy, Competitive Advantage, Capacity Development

\section{Introduction}

Nowadays innovation is one of the mostly used business strategies. In the knowledge era, organizations are acknowledging the necessity of knowledge in their business strategy and attempting to incorporate knowledge in their innovation process. In the competitive global markets, firms are trying to satisfy their customers with their creativity and innovation. Organizations are in an endless struggle of differentiating themselves by continuously introducing new products. The irony is that the market is saturated with many similar (me, too) products. Consumers do not find any significant difference. They (consumers) are indifferent to the products. Relentless effort for innovation, in one hand, is flooding the market with similar products or closely resembled ones and on the other hand, a huge amount of financial and other resources (e.g. physical, technological, intellectual, etc.) are being drained in promoting these products. Firms are being deprived from gaining any benefit from their innovation. In these circumstances, a newer perspective has emerged to gain maximum benefit from both the concepts - in novation and knowledge. This new perspective can be termed as 'knowledge innovation'. Knowledge is the key driver for innovation and organization renewal in the form of capacity development.

\section{Objective, Scope and Importance of the Study}

Innovation is not merely a strategy; it is the result of total organizational effort. Similarly knowledge is a holistic phenomenon. The concept of knowledge innovation conceives both the ideas: knowledge and innovation in a common platform so that either knowledge can be used for innovation or innovation can be more intelligent with the help of knowledge. Indeed, there is a question about how these two concepts can be fitted together. In this connection, this case study will make an attempt to resolve this question in the light of an experience of a medium sized organization in a developing country's (Bangladesh) context.

The objectives of this study are to know -

- The process of incorporating knowledge into the in- 
novation process;

- The method for developing innovative capability with the help of knowledge; and

- The essential factors that make organizations knowledge innovative.

In order to attain the above-mentioned objectives, a number of issues like business strategy, leadership and management style, culture, people management, work system, etc. are required to be examined critically so that a general understanding regarding a knowledge innovative organization can be made.

Managing knowledge for innovation is relatively a new idea. So far, most of the researches have been done in developed countries' scenario. In the era of globalization, competition is widespread; competitors are appearing from cross borders. Businesses of developing countries are facing severe competition. Local businesses are becoming more concerned for their survival. In order to fine-tune with the global business competitiveness, a number of organizations in many developing countries ${ }^{1}$ (Brazil, India, China, etc.) are attempting to pursue knowledge strategy. To follow this trend of globalization, a number of organizations in Bangladesh are also trying to foster knowledge strategy in their business practices. In this study, an organization from Bangladesh has been drawn as sample to understand the application of knowledge in the typical indigenous condition.

It is commonly believed that business strategy is a deliberate effort. This is not always true in the case of knowledge strategy; it could be unconsciously followed by the companies. All the organizations, irrespective of industry, region and/or economy are repositories of a certain set of knowledge. This knowledge-base works as a strategy springboard in the form of culture, style, pattern, leadership and so on. Examining an organization's culture, work pattern, management and leadership style, etc. is also an important part of this case study.

\section{Methodology}

It has already been mentioned that this research has adopted the case study approach. Data and information of this study are basically primary in nature and have been analyzed qualitatively. This exploratory study has made an attempt to explore all the relevant issues with this study and address each of those accordingly. Although, this is a snap-shot study yet this short-term perspective did not hamper the reliability and dependability of the data and information, as well as the findings.

\section{Managing Knowledge for Innovation}

There is a new kind of influence in the global economy -

\footnotetext{
${ }^{1}$ The Policy Forum on Using Knowledge for Development: a unique policy conference jointly organized by the World Bank Institute, the British Council and the OECD, 17 April 2001, Wilton Park, UK. Brazil, China and India participated in this conference in order to share knowledge strategies. www.oecd.org.
}

knowledge. Many scholars have indicated the importance of knowledge for organizational competitiveness and sustainability. Drucker comments "We are moving to a society in which the basic resource of economy is knowledge, instead of capital, labor and natural resources [1]". Stewart believes that "Knowledge has become the preeminent economic resources - more important than raw material; more important, often than money. Considered as an economic output, information and knowledge are more important than automobiles, oil, steel, or any of the products of the industrial age [2]". It (knowledge) is the most strategically important resources of the business [3]. Knowledge is being used more in product design and development, production and distribution. The competitive advantage of the firms can be undercut overnight due to the new knowledge of the competitors. Market leadership, size, name, recognition structure no longer guarantee the survival [4] even the skill and core competency cannot ensure that the firms will be able to capitalize on the new opportunity and tackle new challenges. It is a complete new world with new realities before the marketers.

In the knowledge era, managing knowledge can be an opportunity in new product development, i.e. innovation. There is a broad agreement in favor of using knowledge for innovation. In many instances knowledge and information have been used as major impetus of new product development [5]. According to Verona, the design of new product development work is anchored in knowledge management [6]. Innovation is frequently considered as the primary purpose of knowledge management [7].

Knowledge is also considered as the key impetus for new capability development. Knowledge strategy allows business firm to improve its learning capability to combine knowledge-based capability and make better use of them [8]. Another strategic aspect of knowledge strategy is the continuous interaction with the customers and other related parties. Garcia-Murillo and Annabi opine that customer knowledge is a part of organization knowledge [9]. Through close interaction with the customers, an in-depth understanding is developed which ultimately converts into organization's business knowledge. Constant interaction increases new customer knowledge-base.

\section{Concerns in Using Knowledge for Innovation}

There are few challenges in incorporating knowledge into the innovation process. Neither the literature of innovation management nor knowledge management has focused much on the process of incorporating knowledge in the innovation mechanism. Consequently, there is no clear direction for imparting knowledge into the innovation process; no precise knowledge strategy for innova- 
tion; no suggestion regarding knowledge infrastructure and system.

There is a common understanding that innovation is the result of research and development activities. This is partially true. According to knowledge-based view, creativity and innovation can result from regular business activities and distributed organizational knowledge-base (DOKB). There is another misconception that knowledge is fundamentally related with the new offer development. But the fact is that developing new technology; building new capability; formulating new process and system are with in the jurisdiction of innovation.

Inherently, innovation is uncertain and thus the knowledge innovation is also uncertain [7]. Innovation is perceived as the single most destructive force in an industry [10]. Any form of innovation, such as knowledge innovation may devastate organizations existing capabilities, expertise and knowledge-base.

The roots of all these challenges have institutional implications and the mitigation of these challenges is also dependant on the institutional initiatives. Success depends on how efficiently an organization is managing its knowledge resources. Perez and Pablos consider that it is necessary to manage knowledge effectively in the new economy, because the achievement of sustainable competitive advantage depends on firm's capacity to develop and deploy its knowledge-based resources [11]. Institutional approach is the innate aspect in both the concepts knowledge and innovation.

\section{Case Study: Knowledge Program of Amber Food Limited (AFL)}

Amber Food Limited is one of the promising regional companies in Bangladesh. Currently, the business is offering 55 varieties under 10 product categories. Though it is a relatively new entrant in comparison to other players in the market, yet it could manage a spectacular growth in recent years, soon after its inception.

\subsection{The Early Days - Business Idea and Groundwork}

The idea of establishing a food processing business was conceived after observing the scenario of a favorable environment for agro-based business. Traditionally, Bangladesh is a harvest economy due to the factors like fertile soil, good irrigation system, favorable climate, ample water resources and so forth. In addition to these, entrepreneurs observed a number of institutional supports (e.g. soft loan from Bangladesh Krishi Bank -BKB, tax holiday and tax rebate, and free counseling) from the Government side for the agro-based business as well. The critical success factor in this type of industry is uninterrupted supply of ingredients. In ensuring a smooth procurement of ingredients, the company decided to de- velop a partnership with the local producers (suppliers of the ingredients). It made a special agreement with the farmers in their locality to buy their produce. This had two-fold implications - the business was in a relatively safer condition in procuring ingredients and on the other hand, the farmers had a confirmed buyer.

The entrepreneurs spent two years for planning their business and grooming themselves. During these two years, they tried their best to know market and customer preferences; acquire business exposure and identify key success factors. In the early days, the main challenges were acquiring processing technology, machineries, equipment and skilled workers. They participated in a 6-month course of food processing organized by a private agro-business development NGO (non-government organization) in Bogra. During this course, they realized that it is simply essential to incorporate customer preference in new product development. Otherwise, product would not be desirable to the customers. Side-by-side, they were looking for skilled workers. Fund was not much of a problem for them. They had abundant fertile lands in their villages. They used those lands as collaterals to the bank. All machineries and equipment were procured from China. By the year 1997, the venture was all set to start their business.

\subsection{Commencement of the Business, Contemporary Market Scenario and Initial Business Strategy}

In the year 1998, Amber Food Limited was formally established. In the late 90's, the market was full of imported products from neighboring countries like India, China, Pakistan, Thailand and Bhutan, etc. There were several local players (e.g. Pran, BD Food, Sezan, etc.), too. It was noticed that none of the existing market players were serving in the markets of North Bengal. It appeared to be a potential opportunity for AFL.

Being the consumers in a developing country, Bangladeshis are price-sensitive. Most of the business practices are based on cost-minimization strategy. AFL planned to pursue that along with the emphasis on differentiation, i.e. a hybrid strategy. Economic endowment of upper middle class in Bangladesh though was steady but demonstrated a slow pace of progress. There was a steady growth in demand of differentiated products.

\subsection{Business Development in AFL}

The motto of the business was to provide the best value to its customers. People were at the heart of business development strategy. Strategic agenda of AFL were collecting information about customers; incorporating customers' requirement into the product developing process; reaching new customers with the new range of products and configuring internal state of the business in 
order to support the business strategy.

AFL, on a part-time basis appointed a few students of Rajshahi University to collect information on customers. In collecting data, they targeted two types of respondents - groceries and direct consumers. The part-time workers interviewed groceries and customers in Rajshahi, Bogra, Rangpur and Dhaka city at random. They interviewed only those customers who were buying food products in the market. Within three months of time, ample information was collected. Initially, data was processed manually and later on, electronically. All collected information was categorized in terms of preference, item, price, timing, quantity and frequency. These data and information had a great tactical significance. AFL not only could assess the existing market demand but also assess the future demand as well. In addition, the company could enjoy some other benefits from its knowledge strategy - a direct communication with customers; first-hand market information; better understanding about the distribution channels; new product ideas and so on. In June 1998, AFL started its production and products were marketed in August 1998. Within few months, AFL started getting positive responses from its customers. By 2000, AFL products were available in all major towns in North Bengal and Dhaka city. Since it was a regional company, that is why, it was not possible to assess the exact market share but it definitely became to be the number one company in North Bengal. Also, its presence in Dhaka was strongly felt in terms of market share. Altogether, the overall business performance was satisfactory.

Enthusiastic workers were at the heart of its internal innovation mechanism. Management believed that a person with the right attitude and aptitude can bring about a great change in his/her organization. AFL gave the full freedom to its workers in coming up with new/improved product and process idea. It allowed its workers to spare some time in doing experiments with their innovative ideas. From the motivation point of view, it was a good initiative. By doing and learning, the workforce of AFL became a truly flexible workforce. Employees' performance, creative efforts and team-based productivity were directly related with its compensation package. There was another success in AFL; it could develop an integrated support system with the help of logistics and supply chain, technology and management. (See Figure 1, Figure 2 and Table 1)

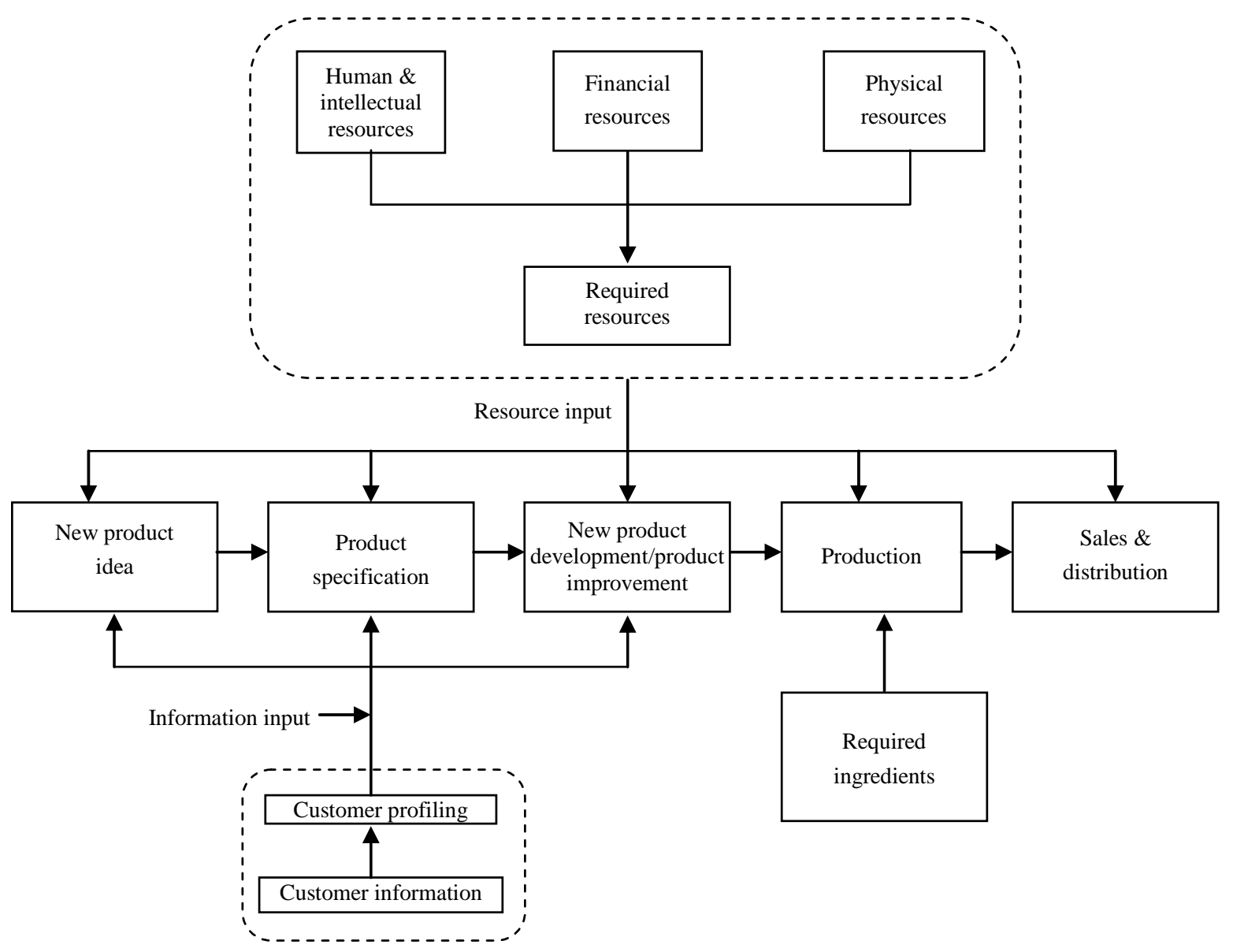

Figure 1. Product development process in AFL 


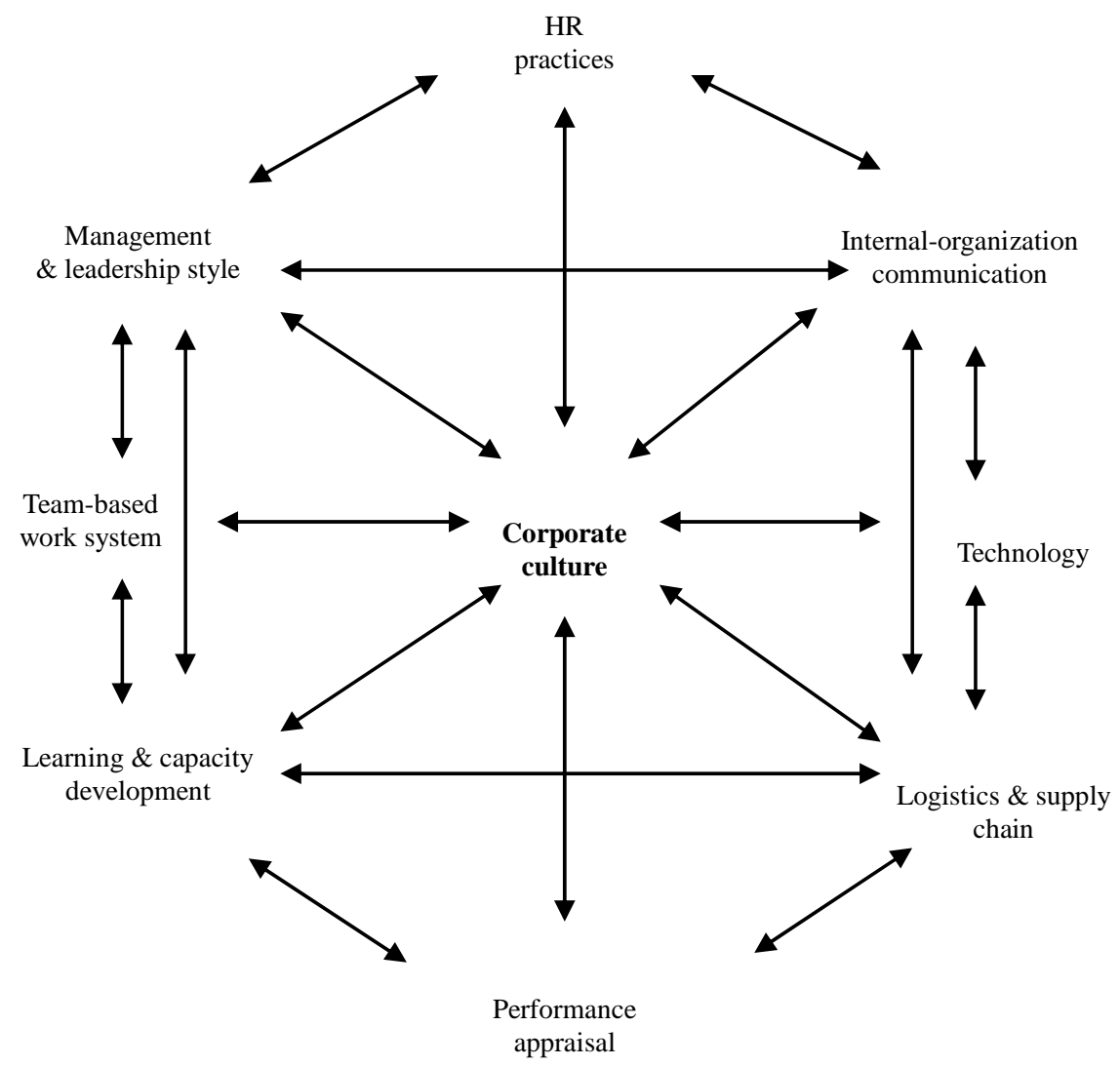

Figure 2. Internal enablers of AFL's business development strategy

AFL kept a keen eye over the changing market phenomena. Therefore, it not only knew what the customers wanted but also to some extent, what the customers might need in the near future. For example, there was an increasing awareness about health and hygiene and increasing demand for dairy products. Its new dairy products became very popular just after the launching. These types of processed and packaged dairy products were not available in Bangladesh. Similarly, there was a growing demand for instant cooking spices as the number of office going female population was increasing with the increase of dual earning families. The increased employment of female workers caused a decreasing trend in home-making service, especially, in the urban areas, since traditional way of preparing spice is cumbersome and time consuming. AFL's instant spices turned into one of the mostly demanded items, especially in the North Bengal region. By considering the changing lifestyle, it (AFL) introduced two new products - mango bar and pickle lozenge under the 'Snacks' category. In 2005, two more new products - tea and energy drink were added in its range under the 'Tea and Beverage' category. Presently, AFL is actively considering expanding its market in other major cities (e.g. Khulna, Chittagong and Barisal) in Bangladesh within the soonest possible time.

\subsection{Looking Beyond the Horizon}

AFL considered that in Bangladesh, food processing companies have a swell future since there is a strong traditional agricultural infrastructure and availability of attractive incentives for the entrepreneurs. SAPTA, among the SAARC countries, had opened a new horizon for export business. 'Pran' (one of the key market players in Bangladesh), had started exporting in the neighboring countries. This phenomenon inspired AFL to do the same. At the end of 2005, AFL decided to expand its market to other neighboring countries like Nepal, India, Afghanistan, etc.

\section{Facts and Findings}

The case content can be perceived from two pints of view:

- To see how all internal components, particularly human resources, technology, logistics, systems and management style, etc. have been integrated for the purpose of innovation; and

- To assess critically the extent the knowledge initiatives along with the knowledge infrastructure were effective in making a knowledge-innovative organization. 


\subsection{Arrangements of Internal Components in AFL}

Internal management system of AFL was basically people oriented. People from inside and outside were integrated into its product development process. Customers contributed in the form of data and information (mainly product idea and preference) and internal stakeholders contributed directly by producing products as per customers' requirements. Each piece of information was used either in developing new products or product improvement, which also instigated new cycles of learning. Eventually, new competencies were developed, which was a clear indication of a learning culture in AFL. Management relied more on its employees; direct supervision was less; rate of error reduced significantly and more experiments were done on new ideas. These were nothing but the outcomes of imparting knowledge into its (AFL) processes and systems. These had two major benefits - product diversity and cost minimization.

In AFL, there was a collective leadership approach. For developing new products, work teams took the basic initiatives and other supporting teams provided support to the new product development initiatives. In case of product improvement, both the product development teams and supporting teams worked together. In coordinating their (teams) activities, there was no formal approach. It depended on the nature of the initiatives and the situation. AFL followed functional structure. By reducing hierarchy, introducing team-based work system and encouraging informal communication system, this functional structure was made dynamic. Trust, involvement and co-operation were the basic elements of AFL culture.
Technology was the inseparable part in AFL. Its new product development ability was primarily based either on adoption of new technology or customizing technology. Products were produced, bottled and packaged by the automatic machines. Technology enabled AFL in attaining economies of scale and in maintaining enhanced product differentiation capability. In analyzing data and information, gradually it started using modern information technology.

Although there was no deliberate HR policy, yet healthy HR practices were there in AFL (See Figure 3). Training and development was replaced by continuous learning; compensation system and performance evaluation were linked with new product development and existing product improvement. There was no set rule or policy for recruitment and selection. However, ever since its establishment, it was recruiting and selecting enthusiastic workers. Therefore, experience of the new workers was irrelevant. Management believed that if a person had a positive attitude towards work, then he/she would become a good performer. Since it was a somewhat flatter organization; the scope of career development was comparatively narrow. Annual increment system could nevertheless, resolve this problem to some extent. Reward system, performance evaluation and compensation management were interlinked. Performance parameters in AFL were: participation, initiative, motivation, multi-skilling, teamwork, idea generation, quality of work and on time delivery. Being a medium scale organization, there was not much distinction between HR and administrative functions and therefore, there was less complicacy in one sense.

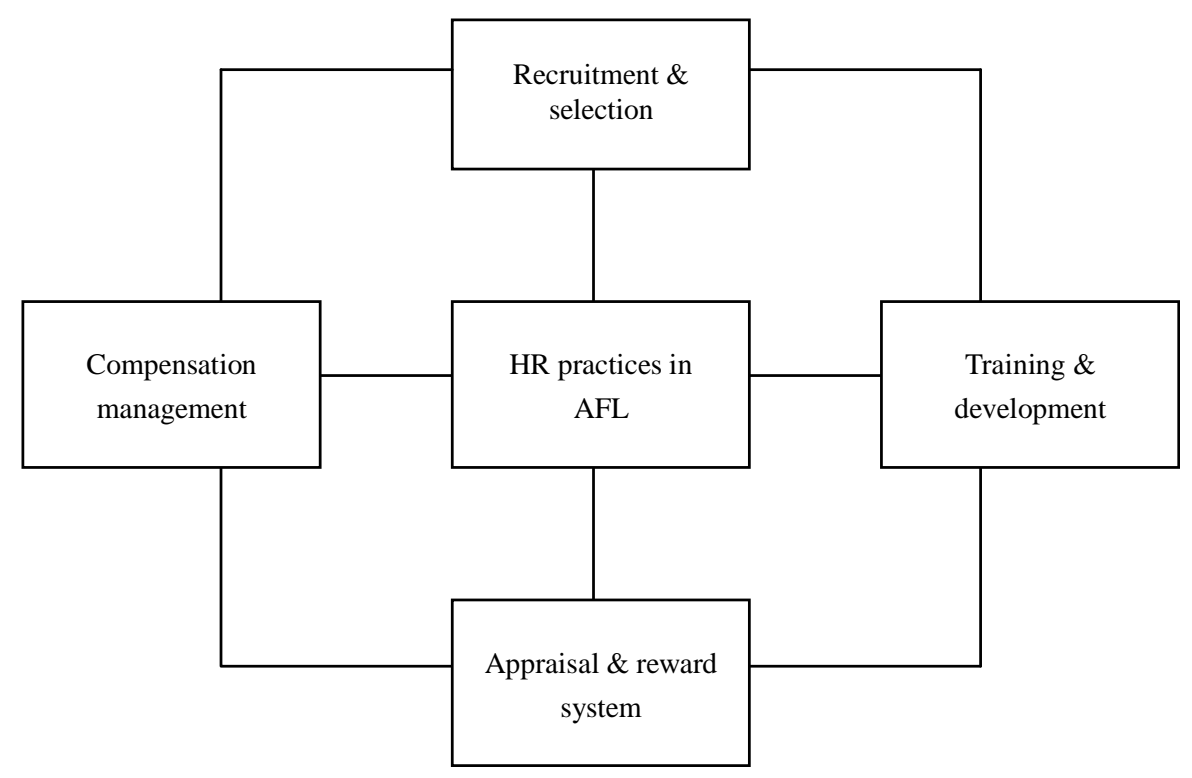

Figure 3. Interlinked HR functions in AFL 
Perhaps the most active enabler was its supply chain. AFL designed its supply chain in such way so that all required supplies and logistics were available on time. The business was very much careful from the very beginning in ensuring the availability of ingredients. Equal emphasis was also given on the distribution of products. Other logistical support like repairing and maintenance, inventory management, etc. were befitting with the operation system.

\subsection{Critical Analysis of the Knowledge Strategy}

According to Van de Van, innovation is a critical mechanism by which firms secure a place in the competitive world of the future [12]. From this point of view, innovation strategy of the business was pretty successful. AFL designed its innovation strategy with the help of knowledge in order to attain competitive advantage. Its (AFL's) key business strategy was to incorporate knowledge, especially, customer knowledge in new product development and to improve existing products by which it could secure its position in the market, and create a competitive advantage. The success of business was on the extent a business could understand its customers and incorporate customer information into its product development process.

AFL had a general understanding of its customers' taste and preference along with their buying behavior. It used to monitor environment relentlessly. Each new piece of knowledge was working as an impetus or a drive for new product development or product improvement. As a result, the firm's product line was extending. This not only could add value to the business but also to the customers. Knowledge only can add value if it is linked with actions, tasks and purposes [7]. Here in AFL, knowledge was linked with collecting customer information, new product development, improving existing products, developing new competencies and satisfying customers. While improving new product and process, knowledge was also adding value to the business. It (knowledge) adds value when it (knowledge) is applied in order to improve, change, or develop specific tasks and activities [13]. AFL improved its existing process and modified its infrastructure whenever necessary as per the merit of the information and knowledge. Overall, it can be said that knowledge was adding value quite noticeably in AFL.

Barton opines that there is a clear linkage in between firm's core capability and new product development [14]. According to Dougherty, product innovation is a primary means of corporate renewal [15]. When AFL used to receive any information from the market, it tried to fit that information into the organization, to see if it was relevant. For instance, when it noticed that the number of working women was increasing in all major cities in Bangladesh, it decided to launch packaged cooking spice.
Before that, the business assessed itself whether it would be feasible. It (AFL) analyzed its existing skill, competency and technology. It was found that some new machineries, few additional skilled laborers, raw materials and packaging materials were needed. For packaging and printing it used its old machines; for distribution it used the same distribution channel and therefore, the overall cost could be minimized significantly. Besides, while launching a new product, AFL acquired new capabilities. Every new product enabled AFL to enhance its existing capacity and/or acquire new capability. Every new product idea was the function of new information on customer and the situation. Eventually, the firm could renew itself along with maintaining its growth in the market. Danneel argues that organizations need to renew themselves continuously for their survival and prosperity in dynamic environments [16].

The most substantial advantage of KM strategy is that it allows improvements of firm's learning capability and its ability to combine knowledge-based capabilities as well as make better use of them [8]. In AFL, individual and organization learning took place simultaneously. Organization learns when a new body of knowledge is imparted with its existing knowledge-base. By processing customer information, noticing changes in the environment and by acquiring new technology, the business was learning. At the same time, employees were learning by experimenting with new ideas, doing tasks, working in a team, directly participating in the product development process and so forth.

Innovation was not a sudden result or outcome rather it was the result of systematic organizational efforts and initiatives. In the knowledge era, 'knowledge' resources and knowledge-based innovation mechanism is at the core of creativity and innovation. Knowledge management strategy refers to the overall change of process, a form of organizational renewal and a focus on innovation through the creation, transmission, and application of new knowledge, which is within the resource-based view of the firm [17]. This holistic approach of knowledge-based innovation or knowledge-driven innovation clearly indicates about the alignment of organizational resources. AFL's management and leadership style was people oriented; employees were encouraged to nurture their creativity and innovativeness; the key HR functions were inter-related and integrated with its new product development and product improvement; high emphasis was given on team-based work; formal and informal communication; imparting knowledge through learning and innovation, etc. These clearly indicate an institutional approach within AFL, which, at the same time implies the alignment of resources, particularly: the intellectual resources in the line of business strategy. A dynamic knowledge infrastructure was thereby created spontaneously. (See Figure 2 and Table 1) 
Table 1: Internal enablers of knowledge strategy in AFL

\begin{tabular}{ll}
\hline \multicolumn{1}{c}{ Enablers } & \\
\hline HR practices & Overall employee satisfaction \\
Performance appraisal & Achievement oriented workforce \\
Management \& Leadership style & Empowerment, participation and involvement \\
Team-based work system & Decentralization and leadership development \\
Inter-organization communication & Shared vision \\
Learning \& capacity development & Capacity development and organizational renewal \\
Technology & Technology alignment and utilization \\
Supply chain and logistics & Smooth procurement and effective support system \\
\hline
\end{tabular}

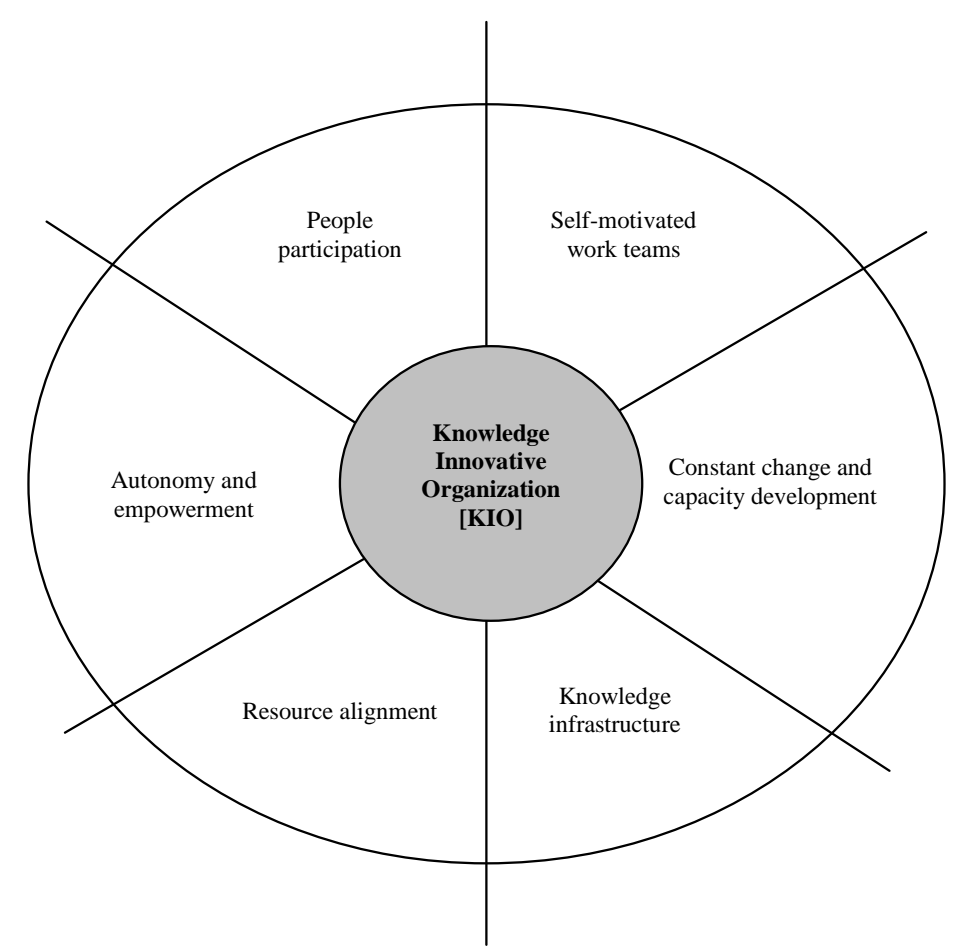

Figure 4. Essential elements of a knowledge innovative organization (KIO)

The most significant finding is that - knowledge strategy in AFL was not deliberate. It was the result of incorporating customer preference into its product development process. Initial thinking of focusing on customers' requirements exerted a breakthrough impact over AFL in terms of organization development, innovation, capability development, and so forth. Knowledge strategy in AFL emerged automatically. In order to sustain the benefits, the business continued to pursue this (KM) strategy which made it a total knowledge innovative organization. All these practices created a total knowledge oriented culture in AFL. This knowledge-based culture was actually playing the key role in making the organization innovative.

\section{Knowledge Innovative Organization}

There is a traditional view that service organizations are primarily considered as knowledge-intensive organization [7]. According to Alvesson [18], knowledge- intensive firms are the companies where most of the works are intellectual in nature and well-educated, and qualified employees are the major part of the workforce. But in making organization knowledge innovative, it is essential to go one step ahead. Knowledge has to be put at the heart of the organization so that it can play a role of a catalyst in guiding business activities, create a knowledge infrastructure, develop knowledge capability through human and institutional development. In AFL, it 
has been observed that in due course of time, it (AFL) could develop a knowledge infrastructure for innovation. This infrastructure consisted of various essential elements like HR best practices, integrated performance appraisal system, management and leadership style, team-based work system, inter-organization communication, learning and capacity development, technology, supply chain and logistics. Core business processes were: autonomy (decentralization of authority), skill development, research and development and socialization. From the experience of AFL case, in general, it is possible to identify several basic elements of a knowledge innovative organization. These are as follows:

1) People (internal and external) integration through socialization.

2) Organizational renewal in the form of capacity development.

3) Alignment and utilization of knowledge resources.

4) Continuous research and development.

5) Knowledge-based infrastructure and logistic system.

The central essence of knowledge innovative organization can be as follows (See Figure 4):

- Employee participation is necessary in business development process with a common vision of innovation.

- Multidisciplinary, self-managed and motivated teams can create diversified knowledge and skill, and ensure the best use of those.

- Successful accomplishment of knowledge strategy mainly depends on the autonomy of the people, socialization with the consumers, flexible organization structure in addition to research and development.

- Knowledge management strategy is involved with constant change. Here, the change is not imposing, rather its natural in the form of capacity development and overall organizational renewal, which is now-a-days termed as human and institutional development.

- Knowledge infrastructure is simply necessary to ensure all logistical support towards knowledge strategy. In addition, there is no specific condition(s) for the successful implementation of knowledge strategy yet organization culture and leadership have a great influence over it.

This knowledge innovative organization has other crucial connotations, too. There are several concerns in using knowledge for innovation. Earlier, it has been discussed that a totalistic institutional approach can resolve these concerns (challenges in using knowledge for innovation). It (AFL) developed its own functional definition of knowledge management. To AFL, knowledge management is imparting customer knowledge into the innovation process through internal capacity development.

\section{Conclusions}

AFL embraced a holistic approach of knowledge strategy. New product development and product improvement were not the sole jurisdictions of marketing department rather all of its units were equally responsible. Sales and marketing was involved in understanding customers' requirements; production department was responsible to produce as per requirements of the customers; human resource was engaged in continuous people development; resources along with logistics were aligned in supporting innovation process; leadership and management was inspiring in fostering teamwork and creativity. AFL's formal and informal systems were playing a key supportive role in creating a social network inside and outside the business.

It is widely believed, since knowledge is a very contemporary thought, therefore, the application of this strategy is limited within the developed countries. But from this case, it is revealed that knowledge has no boundary; it is applicable irrespective of the economy, country and region. There is another conviction that a huge investment is needed in technology, modern equipment and process. But the fact was that, in KM, technology is more involved in the business development process, product development and improvement of mechanism and systems. The central issue is the extent to which organizations are tailoring it (knowledge) as per their requirements. If an organization can customize knowledge strategy according to its need, certainly it would result into long-term competitive advantage. According to Liebeskind, the concept 'knowledge' incorporates and integrates capabilities, structured information and application of technologies in the improvement of products and process and thus, has become a source of competitive advantage [19].

\section{REFERENCES}

[1] P. F. Drucker, “The post capitalist society,” Butterworth-Heinemann, Oxford, 1993.

[2] T. A. Stewart, "Intellectual capital: The new wealth of organizations,” Doubleday, New York, 1997.

[3] M. H. Zack, "Developing a knowledge strategy," California Management Review, Vol. 41, No. 3, pp. 125-145, 1999.

[4] T. Housel and A. H. Bell, "Measuring and managing knowledge,” McGraw-Hill Irwin, New York, 2001.

[5] M. Grant, "Toward a knowledge-based theory of the firm,” Strategic Management Journal, Winter Special Issue, Vol. 17, pp. 109-122, 1996.

[6] G. A. Verona, "Resource-based view of product development,” Academy of Management Review, Vol. 24, No. 1, pp. 132-142, 1999. 
[7] S. Newell, M. Robertson, H. Scarbrough, and J. Swan, “Managing knowledge work,” Palgrave, New York, 2002.

[8] B. Kogut and U. Zander, "Knowledge of the firm, cognitive capabilities and replication of technology," Organisation Science, Vol. 3, No. 3, pp. 383-397, 1992.

[9] M. Garcia-Murillo and H. Annabi, "Customer knowledge management," The Journal of the Operational Research Society, Vol. 53, No. 8, pp. 875-884, 2002.

[10] J. Kay, "Foundations of corporate success," Oxford University Press, Oxford, 1993.

[11] J. R. Perez and P. O. Pablos, "KM and organizational competitiveness: A framework for human capital analysis,” Journal of Knowledge Management, Vol. 7, No. 3, pp. 82-91, 2003.

[12] A. M. Van de Van, "Central problems in the management of innovation”, Management Science, Vol. 32, No. 5, pp. 590-607, 1986.

[13] R. McDermott, "Why information technology inspired but cannot deliver knowledge management," California Management Review, Vol. 41, No. 4, pp.103-117, 1999.
[14] D. Leonard-Barton, "Core capabilities and core rigidities: A paradox in managing new product development," Strategic Management Journal, Summer Special Issue, Vol. 13, pp. 111-125, 1992.

[15] D. Dougherty, "A practice-centered model of organizational renewal through product innovation," Strategic Management Journal, Summer Special Issue, Vol. 13, pp. 77-92, 1992.

[16] E. Danneels, "The dynamics of product innovation and firm competences,” Strategic Management Journal, Vol. 23, No. 12, pp. 1095-1121, 2002.

[17] W. M. Cohen and D.A. Levinthal, "Absorptive capacity: A new perspective on learning and innovation," Administrative Science Quarterly, Vol. 35, No.1, pp. 128-135, 1990.

[18] M. Alvesson, "Knowledge work: ambiguity, image and identity,” Human Relations, Vol. 54, No. 7, pp. 863-886, 2001.

[19] J. P. Liebeskind, "Knowledge, strategy and theory of firm,” Strategic Management Journal, Winter Special Issue, Vol. 17, pp. 93-107, 1996. 